\title{
Uma Avaliação da Política Monetária nos Regimes de Metas Cambiais e de Metas para Inflação
}

\section{An Evaluation of Monetary Policy in Exchange Rate and Inflation Targeting Regimes}

\author{
Filipe Rodrigues dos Santos* \\ Luckas Sabioni Lopes** \\ Thiago Costa Soares*** \\ Luiz Antônio de Lima Júnior****
}

\begin{abstract}
Resumo: Este artigo objetiva comparar o desempenho da condução da política monetária nos regimes de câmbio administrado e de metas para inflação no período pós-Plano Real (1995-2014). Para tanto, estimam-se modelos de regressões autovetorais (VAR) com dados mensais no período considerado. As estimações mostram que, sob o regime de âncora cambial, a autoridade monetária não foi capaz de controlar adequadamente o indicador de inflação. Os choques nos juros não impactaram os preços e surtiram efeitos altamente recessivos sobre o produto. No regime de metas para inflação, verifica-se significativa influência da taxa básica de juros sobre o produto, as expectativas de inflação e a inflação efetiva. As análises em diferentes amostras durante o regime de metas mostram, contudo, uma perda de eficácia da política monetária entre os anos de 2010 e 2014. Conclui-se, portanto, que a simples adoção do regime de metas não é garantia de bom desempenho da política monetária no Brasil. A capacidade de ajustar a economia depende crucialmente do comprometimento do Banco Central com as boas práticas que fundamentam a abordagem.
\end{abstract}

Palavras-chave: Política monetária. Câmbio administrado. Metas para a inflação. VAR. Brasil.

Abstract: In this paper, we evaluate the macroeconomic performance of monetary policy conduction under the crawling peg (CP) and inflation targeting (IT) in Brazil, both implemented after the Real Plan. In order to do so, we estimate several autoregressive (VAR) regressions with monthly data in the 1995-2014 period. Our findings show that during the crawling peg system (1995 to June-1999), the monetary authority was not able to affect inflation in the country. Interest rate innovations had no significant impacts on prices, and highly recessive effects on output. After the inflation targeting implementation (July-1999 to 2014), we verify that policy rate shocks reduced output, consumer prices inflation, and

* $\quad$ Mestre em Economia Aplicada pela Universidade Federal de Juiz de Fora (UFJF). E-mail: filipers. mg@gmail.com

** $\quad$ Doutor em Economia Aplicada pela Universidade Federal de Viçosa (UFV). Professor adjunto do Departamento de Economia da Universidade Federal de Juiz de Fora, campus Governador Valadares (UFJF). E-mail: luckas.lopes@ufff.edu.br

*** Doutor em Economia Aplicada pela Universidade Federal de Viçosa (UFV). Professor adjunto do Departamento de Economia da Universidade Federal de Juiz de Fora, campus Governador Valadares (UFJF). E-mail: thiago.costa@ufjf.edu.br

**** Doutor em Economia Aplicada pela Universidade Federal de Juiz de Fora (UFJF). Professor adjunto do Departamento de Economia da Universidade Federal de Juiz de Fora, campus Governador Valadares (UFJF). E-mail: luiz.lima@ufff.edu.br 
inflation expectations. However, between 2010 and 2014 specifically, monetary policy lost much of its effectiveness. Thus, we conclude that inflation targeting has improved the outcomes of monetary policy in Brazil, but such result depends crucially on the commitment of the Central Bank with the fundamentals of this framework.

Keywords: Monetary policy. Crawling peg. Inflation targeting. VAR. Brazil.

JEL Classification: E52; E32.

\section{Introdução}

Lançado em 1994, o Plano Real obteve êxito no controle dos níveis de preços e interrompeu um longo processo de inflação instável e persistente que se agravara em meados da década de 1980. Os desafios posteriores à implementação do plano se concentraram em manter a inflação controlada e, além disso, afetar a formação de expectativas dos agentes econômicos. Para isso, optou-se pela utilização de âncoras nominais, tais como o regime de câmbio administrado, vigente entre 1995 e 1999, e o de metas para inflação, utilizado desde então.

Durante o regime de âncora cambial, adotou-se uma política de câmbio fixo na forma de um crawling peg, ${ }^{1}$ em que a taxa de câmbio nominal sofreria ajustes a uma taxa baixa e prefixada (PASTORE, 2015). Em que se pese o sucesso inicial dessa política monetária, com o passar do tempo os problemas decorrentes da administração cambial em um contexto de diversos choques externos começaram a se tornar um grave empecilho para a economia brasileira, ocasionando, mais à frente, o abandono do regime. Lançado em meados de 1999, o regime de metas para inflação ainda vigora no país. Nessa abordagem, o Banco Central do Brasil (BCB) se compromete a agir de forma que a inflação observada da economia esteja em conformidade com uma meta preestabelecida, anunciada pública e antecipadamente (MOENJAK, 2014).

O ramo da literatura que procura comparar o desempenho dos dois regimes monetários no Brasil é relativamente recente e bastante ativo. Minella et al. (2003), por exemplo, estimaram funções de reação (regras de Taylor) e autorregressões vetoriais (VAR, do inglês vector autoregression) com o objetivo de avaliar a política monetária sob o regime de metas para inflação no período de 1999 a 2002, com dados mensais. Os autores constatam que o $\mathrm{BCB}$, por meio de sua política monetária, reagiu fortemente às expectativas de inflação e às pressões inflacionárias, bem como conseguiu manter as expectativas de mercado sob controle, mesmo na presença de choques inflacionários.

Arquete e Jayme Júnior (2003) e Minella (2003) procuram, através da metodologia VAR, examinar a política monetária brasileira no período pós-Plano Real.

1 Crawling peg é um regime cambial no qual a taxa de câmbio é permitida apreciar ou depreciar de forma gradual (PASTORE, 2015). 
Segundo Arquete e Jayme Júnior (2003), que analisam o período de 1994 a 2002 com dados mensais, a política monetária via taxa de juros teve dificuldades no controle da inflação, dado que houve indícios do efeito price puzzle. ${ }^{2}$ Por sua vez, Minella (2003) investiga os impactos da política monetária sobre a inflação, o produto e alguns agregados monetários para três períodos distintos entre janeiro de 1975 e dezembro de 2000 . Os principais resultados obtidos mostram que a política monetária teve efeito significativo sobre a produção e os agregados monetários em todas as amostras. Somente no terceiro período, 1994-2000, os choques na política monetária impactaram negativamente a inflação, contudo esse resultado foi bastante sensível à escolha do modelo.

Ao comparar os efeitos da política monetária sob o regime de câmbio administrado e o de metas para inflação entre 1994 e 2006, com dados mensais, Barbosa (2008) encontra evidências de que o crescimento econômico tem sido mais devagar e menos volátil no regime de metas. $\mathrm{O}$ autor argumenta que o regime de metas obteve sucesso em reduzir a inflação e a taxa de juros real da economia após os choques cambiais de 2002 e 2003. A principal lacuna dessa pesquisa é, contudo, a ausência de um método estatístico que pudesse controlar fatores exógenos e propiciar resultados mais robustos.

Arestis, Paula e Ferrari-Filho (2009), em um estudo para países emergentes, incluindo o Brasil, concluem que a adoção do regime de metas, apesar de ter coincidido com um período de queda nas taxas de inflação, não foi responsável por tal fenômeno, uma vez que as nações que utilizaram outros regimes monetários também experimentaram variações menores no indicador de preços agregados. Não obstante, parece haver um problema com as amostras selecionadas pelos referidos autores. Por exemplo, ao compararem o período anterior e posterior à implantação do regime de metas, dividiram a base de dados entre 1995-1998 (pré-regime) e 1999-2005 (pós-regime), sendo que a nova política entrou em vigor apenas em junho de 1999. Ademais, não fizeram nenhuma ponderação com respeito aos choques cambiais ocorridos em 1999 e 2002.

Mello e Moccero (2011) objetivam analisar os efeitos do regime de metas para inflação no Brasil, Chile, Colômbia e México com a estimação de um modelo novo keynesiano e regressões VAR. A amostra do estudo varia entre 1996 a 2006, com dados mensais. Ao verificarem a função de reação do BCB, os autores concluem que a política monetária tem respondido com maior intensidade às movimentações da inflação esperada, tornando-se mais forward-looking. Entretanto, não encontraram efeitos significativos do regime de metas sobre a redução da volatilidade do produto e da taxa de juros. Uma consideração importante a ser feita

2 O efeito price puzzle acontece quando ocorre a elevação da taxa de inflação logo após um choque positivo na taxa de juros. 
sobre esse estudo é que as estimações VAR apresentaram sinais do price puzzle, o que a literatura sugere ser reflexo de variáveis omitidas (SIMS, 1992).

Por outro lado, Tomazzia e Meurer (2009) e Mendonça, Medrano e Sachsida (2010) estimam modelos VAR que se distinguem dos tradicionais, adotados pela literatura citada previamente. No primeiro caso, foram adotadas especificações VAR em nível, seguindo a metodologia de Toda e Yamamoto (1995), no período de junho de 1999 a dezembro de 2008. Tais autores verificaram efeitos negativos dos choques da taxa de juros sobre a inflação e sobre a produção industrial, especialmente no setor de bens de consumo duráveis e no de bens de demanda industrial.

No caso de Mendonça, Medrano e Sachsida (2010), foi utilizada a técnica de restrição de sinal na função impulso-resposta, proposta por Uhlig (2005), a qual delimita a resposta da inflação a valores negativos em reação aos choques positivos nos juros. A justificativa, baseada em Sims (1992), é dada pela incapacidade dos modelos VAR tradicionais de capturar o componente forward-looking da política monetária. Assim, se os bancos centrais esperam inflação mais alta no futuro e reagem hoje alterando a taxa básica, as funções estimadas poderiam indicar uma resposta positiva da inflação às variações nos juros. A amostra analisada pelos autores variou entre julho de 1999 e maio de 2010. Foi possível concluir que a produção real e a inflação responderam negativamente às variações da taxa básica no país.

Dessa forma, é possivel perceber que a literatura a respeito dos efeitos da adoção do regime de metas para inflação no Brasil ainda apresenta resultados mistos em função de amostras pouco adequadas para a análise da política, da possível má especificação dos modelos analíticos e/ou da não consideração do regime de metas para inflação em contexto com a política adotada anteriormente. Assim, o presente trabalho procura contribuir com a literatura no país, comparando o desempenho da política monetária nos regimes adotados desde o início do Plano Real. Especificamente, objetiva-se estudar qual dos dois regimes (de metas cambiais ou de inflação) proporcionou melhores resultados no que concerne à estabilização da economia brasileira, principalmente da inflação, da taxa de juros e do produto.

A metodologia utilizada baseia-se na estimação de modelos VAR em nível (TODA; YAMAMOTO, 1995), pois tendem a eliminar o problema do price puzzle. Assim, em primeiro lugar, estimam-se regressões para dois períodos distintos, o primeiro entre janeiro de 1995 e junho de 1999, caracterizando o regime de âncora cambial, e o segundo entre julho de 1999 e dezembro de 2014, em que vigorou o regime de metas para inflação. Em seguida, com o intuito de analisar diferenças na condução da política dentro do regime de metas, a segunda amostra é dividida em três outros períodos, de julho de 1999 ao fim de 2004, de janeiro de 2004 a dezembro de 2009 e de janeiro de 2010 a dezembro de $2014 .{ }^{3}$ Tal procedimento

3 Há uma sobreposição proposital entre os dois primeiros períodos. Tal procedimento foi adotado 
é interessante uma vez que aproxima o tamanho das amostras do período do sistema de metas para a inflação à do sistema cambial. Além disso, ele permite uma análise em três contextos econômicos diferentes: o primeiro, quando o regime de metas ainda era recente e sofreu diversos choques; o segundo, em que a política monetária seguiu mais de perto o que ficou conhecido como "tripé macroeconômico"; e, o terceiro, dominado pelo que se convencionou chamar de nova matriz econômica (PASTORE, 2015).

Esta pesquisa envolve, além desta introdução, mais quatro seções: a segunda expõe os fundamentos operacionais das âncoras nominais de câmbio e de metas para inflação, além de uma breve descrição sobre os mecanismos de transmissão da política monetária; a terceira apresenta o modelo VAR estimado para a comparação dos dois regimes, bem como a base de dados; a quarta discute os principais resultados da pesquisa; e, por fim, a quinta apresenta as considerações finais do trabalho.

\section{Contextualização e Referencial Teórico}

Como o objetivo deste trabalho é comparar o desempenho macroeconômico dos regimes de âncora cambial e de metas para inflação implementados desde o início do Plano Real, torna-se necessário conhecer o modo operacional de ambas as abordagens de política. Desse modo, a presente seção tem como propósito explicitar o funcionamento, as vantagens, as desvantagens e a forma como estes regimes foram conduzidos pelo Banco Central do Brasil.

\subsection{O Regime de Câmbio Administrado e sua Aplicação no Brasil}

Uma âncora cambial pode assumir diferentes formas. Uma delas se baseia na fixação do valor da moeda doméstica em relação a uma commodity. Nesse caso, um exemplo prático seria o padrão ouro que vigorou de 1870 até 1914, na Primeira Guerra Mundial (SENNA, 2010). Em outra formulação, atrela-se o valor da moeda doméstica em relação à moeda de um país com baixa inflação. Como exemplos, têm-se o sistema Bretton Woods, adotado em 1944, e o currency board, adotado pela Argentina em 1991. Uma terceira forma consiste em fixar, por meio de uma regra ou estratégia, a evolução do valor da moeda doméstica ao valor da moeda de um país estável. Nesse caso, o crawling peg e o regime de bandas cambiais são bons exemplos (MOENJAK, 2014).

para balancear as amostras com, no mínimo, quatro anos e meio de duração, isto é, 54 pontos mensais. Dessa forma, as estimativas foram obtidas com um número razoável de graus de liberdade. 
No Brasil, após o êxito inicial do Plano Real, quando a taxa de inflação, medida pelo Índice de Preço ao Consumidor Amplo (IPCA), reduziu de 47\%, em junho de 1994 , para $6,84 \%$, em julho do mesmo ano, e depois para $2,1 \%$ no restante do ano, houve a necessidade de um novo balizador para a formação de preços na economia. Anteriormente, devido à convivência por décadas com um ambiente inflacionário, os agentes econômicos passaram a formar seus preços com base em quase moedas indexadas, que eram atreladas à variação diária da taxa overnight. A súbita estabilização ocorrida após 1994, entretanto, estimulou a procura por novas estratégias. Assim, inspirado em planos de estabilização de países como México e Argentina, o Brasil optou por adotar uma âncora cambial (SOUZA, 2005).

Segundo Pastore e Pinotti (1999), em março de 1995 o Brasil adotou formalmente um sistema de bandas cambiais, estabelecendo os limites de flutuação entre R $\$ 0,86 /$ US $\$ 1$ e R $\$ 0,90 /$ US $\$ 1$. Ainda em março desse ano, os limites das bandas foram corrigidos e fixados entre $R \$ 0,88 /$ US $\$ 1$ e $R \$ 0,93 /$ US $\$ 1$. Contudo, novamente no ano de 1995 houve a mudança do regime cambial, com a adoção do sistema de crawling peg (PASTORE, 2015).

Segundo Moenjak (2014), uma das vantagens de uma âncora cambial é a possibilidade de se fixar o valor da moeda doméstica a de outro país que tenha um histórico de baixas taxas de inflação. Desse modo, gera-se, dentro de certos limites, a convergência da taxa de inflação doméstica à do país âncora.

Pelo lado das desvantagens, Obstfeld e Rogoff (1995), Calvo e Mishkin (2003) e Senna (2010) destacam que esse regime geralmente implica perda da independência da política monetária, dado que o banco central fica em uma posição acomodatícia, sendo forçado a "importar" problemas que porventura ocorram no país cuja moeda está servindo de referência. Ademais, para Mishkin (1998), uma importante crítica associada ao regime de âncora cambial se deve ao fato de que a economia doméstica se torna mais vulnerável a ataques especulativos, que acabam desencadeando sérias crises cambiais e, por conseguinte, financeiras, como as ocorridas no país durante toda a década de 1990 (crises do México, dos Tigres Asiáticos e da Rússia).

De acordo com Senna (2010), a perda das reservas domésticas brasileiras decorrentes do contágio das crises financeiras se deu de forma intensa. A reação costumeira do BCB para impedir a constante fuga de capitais era aumentar intensamente a taxa de juros básica. Concretamente, durante a crise asiática a taxa de juros dobrou de 20,7\% para 40,9\% a.a., alcançando valores ainda maiores em seguida. Essa estratégia foi bem-sucedida nos dois primeiros eventos, quando as reservas internacionais retornaram para seus níveis iniciais em poucos meses. Porém, os custos econômicos e o peso sobre as contas públicas de tais medidas, em conjunção com a perda de eficácia da política durante a crise russa, levaram ao abandono do regime de metas cambiais em janeiro de 1999. 


\subsection{O Regime de Metas para Inflação e sua Aplicação no Brasil}

De acordo com Moenjak (2014), o sistema de metas para inflação é um regime monetário no qual o banco central tem como objetivo manter a variação dos preços próxima a um valor pré-determinado. Utiliza-se a taxa de juros como principal instrumento de ajustes da economia, de modo que a taxa de inflação, ou mais especificamente as expectativas de inflação, fiquem dentro da meta estabelecida.

Mishkin (2007) cita alguns aspectos operacionais que os bancos centrais utilizam para a efetivação do regime. O primeiro se refere ao horizonte de tempo necessário para o instrumento de política monetária conduzir a inflação para o centro da meta estabelecida. Em decorrência da presença de contratos salariais, preços e expectativas rígidas e do fato de a política monetária agir com defasagens de tempo, a convergência da taxa de inflação para a meta pode não se dar de forma imediata. Assim, Mishkin (2000) pondera que períodos curtos de tempo talvez possam não ser suficientes para que a política alcance seu objetivo.

A segunda característica se refere à escolha do banco central por uma meta pontual ou por uma banda. No caso de uma banda, tem-se um intervalo de tolerância para cima ou para baixo, em torno do qual a meta de inflação pode oscilar. Segundo o Banco Central do Brasil (2015), a utilização de bandas é preferível à utilização de uma meta pontual pelo fato de que não se possui controle perfeito sobre os níveis de preços. A existência de bandas permite aos bancos acomodarem os choques que afetam a economia, dando maior flexibilidade à política.

No que concerne à escolha do valor numérico da meta para a inflação, Almeida e Goodhart (1998), Bernanke et al. (2001) e Mishkin (2001) sugerem uma meta levemente acima de zero por duas razões. Em primeiro lugar, uma inflação acima de zero por um período longo de tempo não abalou a credibilidade dos bancos centrais quanto ao compromisso com a estabilidade de preços. Em segundo lugar, pode ser arriscado ter uma meta para inflação igual a zero. Tal política pode levar a economia a momentos de deflação, causando instabilidade financeira e tornando o uso da política monetária mais trabalhosa.

Sobre as vantagens do regime de metas para inflação, Mishkin (1998) destaca o fato de que, em contraste com o regime de âncora cambial e regras de crescimento monetário, as metas para inflação possibilitam maior flexibilidade. Além disso, o regime de metas é facilmente entendido pelo público, sendo assim bastante transparente. Outra importante vantagem do regime é a tendência a aumentar a prestação de contas dos bancos centrais para com a sociedade.

Por outro lado, Mishkin (2007) cita três principais críticas que são comumente associadas com a adoção do regime de metas. A primeira argumenta que se coloca uma regra rígida sobre a política monetária, desse modo impedindo que tenha capacidade suficiente para agir em circunstâncias não previstas, como um 
choque de oferta, por exemplo. Segundo, em razão das defasagens existentes, os resultados da política monetária sobre a inflação podem ser verificados somente após um período de tempo. Terceiro, associa-se o regime ao baixo crescimento da economia e do emprego, uma vez que poderia dar uma ênfase excessiva ao controle dos preços.

O regime de metas para inflação foi adotado formalmente no Brasil em 21 de junho de 1999, através da edição do Decreto $n^{\circ} 3.088$ pelo Presidente da República. O Conselho Monetário Nacional (CMN) é o responsável por estabelecer o valor numérico da meta de inflação, cabendo ao Comitê de Política monetária (Copom) do BCB realizar o cumprimento da meta. No regime brasileiro, escolheu-se como medida de inflação o IPCA, que é calculado pelo IBGE. Caso o BCB não cumpra as metas de inflação, o presidente da instituição deve emitir uma carta aberta ao ministro da fazenda, explicando as causas da não realização da política, as medidas a serem tomadas para garantir que a inflação volte para a meta e o período de tempo necessário para a sua convergência (BANCO CENTRAL DO BRASIL, 2015).

$\mathrm{Na}$ experiência brasileira com o regime de metas entre 1999 e 2014, a taxa de inflação ficou dentro da banda em boa parte do tempo. As metas foram cumpridas em 13 dos 16 casos, ficando acima do limite superior nos anos de 2001, 2002 e 2003. De acordo com Goldfajn e Muinhos (2011), as principais causas para tais descumprimentos foram as desvalorizações cambiais. Entre 2004 e 2014, a inflação se situou no intervalo definido pela autoridade monetária. O restante do artigo procura verificar se tal mudança na política produziu efeitos positivos para a economia brasileira.

\subsection{Política Monetária e seus Mecanismos de Transmissão}

Segundo Taylor (1995), os canais de transmissão da política monetária são mecanismos pelos quais as ações do banco central surtem efeitos na economia e se refletem em indicadores como inflação, produto, emprego e taxa de câmbio, dentre outros. Mishkin (2009) classifica os principais canais de transmissão da política monetária como: a) canal da taxa de juros (ou clássico); b) canal da taxa de câmbio; c) canal do preço dos ativos; d) canal de crédito; e e) canal das expectativas.

Para Mendonça (2001), o canal de transmissão da política monetária por meio da taxa de juros é o mais conhecido. No caso, por exemplo, de uma política expansionista feita pelo banco central, tem-se uma maior quantidade de moeda disponível em circulação, o que pressiona a taxa de juro de curto prazo para baixo e, com isso, expandem-se os dispêndios com consumo e investimento (uma vez 
que os efeitos da política monetária se propagam pela estrutura de termo da taxa de juros). Por fim, gera-se um efeito altista na produção e nos preços agregados.

Tal mecanismo tem sido amplamente debatido na literatura empírica brasileira. Estudos baseados em modelos VAR tradicionais tendiam a apresentar baixa elasticidade da inflação aos juros. ${ }^{4}$ Avanços recentes, porém, têm alterado essa visão. Por exemplo, para o período pós-regime de metas, Tomazzia e Meurer (2009), utilizando a abordagem VAR proposta por Toda e Yamamoto (1995), mostram que a inflação e a produção dos setores de bens de consumo duráveis, de bens intermediários e de capital respondem negativamente à política de aumento dos juros. Mendonça, Medrano e Sachsida (2010), estimando regressões vetoriais com o método de restrição de sinais de Uhlig (2005), chegam a resultados semelhantes para a inflação e o PIB. Por sua vez, Lopes, Chauvet e Lima (2018), adotando um modelo novo-keynesiano estimado com técnicas bayesianas no período de 1975 a 2012, encontram que o controle da inflação após o início do Plano Real foi em boa parte devido ao maior peso dado às flutuações dos preços na função de reação do $\mathrm{BCB}$. A não utilização de mecanismos de controle direto de preços é outro elemento que facilita a implementação e a efetividade da política monetária, segundo estes autores. Contudo, não foram encontradas evidências de que a volatilidade do produto seja afetada pela política monetária no país.

Outro canal de transmissão de política monetária é o da taxa de câmbio. De acordo com Mishkin (2007), existem dois principais mecanismos que operam através da taxa de câmbio: o primeiro se dá por meio das exportações, que são estimuladas quando a política expansionista dos bancos centrais gera desvalorização da moeda nacional; o segundo ocorre através do balanço patrimonial das empresas. Como determinadas empresas têm dívidas em moeda estrangeira, uma expansão monetária pode ter impacto negativo, uma vez que a desvalorização cambial aumenta o valor das obrigações mensuradas em moeda nacional. A literatura que relaciona o câmbio com a política monetária brasileira tem se atentado a outra questão, entretanto: a da magnitude do efeito pass-through, que indica a resposta da inflação às desvalorizações cambiais. A esse respeito, Correa e Minella (2010) constatam que esse efeito pode ser não linear, sendo os repasses maiores nas expansões e nas ocasiões de choques elevados do câmbio. Pimentel, Luporini e Modenesi (2016), também analisando repasses assimétricos, argumentam que o pass-through é maior nas depreciações do que nas apreciações cambiais. Entretanto, Tejada e Silva (2008) indicam que, de maneira geral, os efeitos inflacionários dos repasses cambiais são pequenos.

4 Ver Arquete e Jayme Júnior (2003), Minella (2003), entre outros. Nesses artigos, o efeito contracionista se dá em maior magnitude sobre o produto. 
O terceiro canal é o dos preços dos ativos, o qual pode afetar o investimento e o consumo das famílias. Para a análise dos efeitos sobre os investimentos privados, é útil aplicar a teoria do $q$ de Tobin (TOBIN, 1969). O q de Tobin pode ser afetado pela política monetária da seguinte maneira: uma expansão monetária reduz as taxas de juros, tornando os títulos públicos menos atrativos. Tal movimento pode estimular a demanda por ações e, consequentemente, o seu preço. Com o aumento dos preços das ações, o $q$ de Tobin se eleva e estimula a realização de investimentos. Ademais, a expansão monetária acarreta, via preço dos ativos, aumento na riqueza, o que tende a estimular o consumo agregado. Resultados empíricos acerca desses fenômenos para a economia brasileira ainda são incipientes, podendo-se destacar o estudo de Nunes, Costa Júnior e Meurer (2005), que não encontra evidências de que a taxa básica de juros impacte significativamente os retornos de mercado (da Bolsa de São Paulo, a Bovespa). Quanto aos efeitos da política monetária sobre o preço dos títulos públicos, sugere-se a ótima revisão de Tomazzia e Meurer (2009).

O quarto canal é o de crédito. Como argumentado por Mishkin (2009), os empréstimos bancários são de alta relevância nesse contexto, dada a capacidade que os bancos têm de reduzir os problemas de assimetria de informação nos mercados financeiros. Dessa maneira, uma política monetária expansionista, a qual aumenta as reservas bancárias, eleva a quantidade de recursos disponíveis para empréstimos. Como muitas das atividades econômicas necessitam de empréstimos bancários para sua realização, como o investimento e o consumo, a expansão do crédito tende a elevar o nível da demanda agregada e o produto. Pesquisas iniciais desse mecanismo de transmissão para o caso brasileiro foram conduzidas por Takeda, Rocha e Nakane (2005) e Carneiro, Salles e Wu (2006). No primeiro estudo, os autores concluem que as elevações nos juros não afetam negativamente a liquidez bancária e a possibilidade de se aumentar a oferta de crédito. Ao contrário, Carneiro, Salles e Wu (2006) atestam que a relevância do canal de crédito se dá pelos efeitos negativos da taxa de juros sobre a demanda por crédito no setor empresarial. Ademais, estudos mais recentes sugerem que a política monetária contracionista também impacta negativamente a oferta de crédito bancário em termos gerais (BEZERRA; LIMA; SILVA, 2016) ou aqueles destinados à produção (DUTRA; FEIJÓ; BASTOS, 2017).

Por fim, o canal das expectativas procura verificar como as ações do banco central, por meio de alterações na taxa de juros de curto prazo, afetam as expectativas dos agentes econômicos quanto à dinâmica futura da economia (MENDONÇA, 2001). Por exemplo, se o policymaker provoca um aumento na taxa de juros com o objetivo de evitar um processo inflacionário, geram-se efeitos negativos em curto prazo (como uma retração do produto). Porém, essa medida pode reduzir 
as taxas de inflação esperadas e, via efeito Fisher, ${ }^{5}$ as taxas de juros esperadas em longo prazo. Dessa maneira, lançam-se as bases para a recuperação da economia. As evidências de uma estrutura de termo das taxas de juros balizada pela teoria das expectativas, contudo, são ainda iniciais no país (LIMA; ISSLER, 2003; MARÇAL; VALLS PEREIRA, 2007). Assim, pesquisas adicionais são necessárias para se testar a argumentação de que as variações nas taxas de curto prazo, controladas pelo $\mathrm{BCB}$, afetam as taxas longas.

Na próxima seção apresenta-se o modelo econométrico que inclui variáveis que representam o produto, a inflação, a expectativa inflacionária, os juros de curto e de longo prazo, o câmbio e o volume de moeda e de crédito. Abordam-se, portanto, várias das hipóteses mencionadas.

\section{Metodologia}

Nesta seção será apresentado o modelo VAR a ser estimado, a função impulso-resposta e a decomposição da variância, técnicas que irão dar suporte à análise das hipóteses levantadas na introdução. Também são apresentados os dados, com suas respectivas fontes, periodicidades e tratamentos.

\subsection{Modelo de Vetores Autorregressivos (VAR)}

Segundo Bueno (2012), o modelo VAR é composto de uma equação para cada variável estudada, as quais incluem os valores defasados dessa variável e das outras incluídas do modelo. Um VAR com $p$ defasagens e $k$ variáveis pode ser descrito em sua forma matricial por:

$$
Y_{t}=\alpha+\theta_{1} Y_{t-1}+\ldots+\theta_{p} Y_{t-p}+e_{t}
$$

em que $Y_{t}$ é um vetor coluna com $k$ variáveis endógenas; $\alpha$ é um vetor de interceptos; $\theta_{i}, i=1,2,3, \ldots, p$ são matrizes $k x k$ de coeficientes a serem estimados; $e_{t}$ é um vetor de erros aleatórios com média zero, $E\left(e_{t}\right)=0$, e matriz de variâncias e covariâncias definida por $E\left(e_{t} e_{t}{ }^{\prime}\right)=\Sigma$; $p$ representa o número de defasagens do modelo. No presente trabalho, as variáveis que compõem o vetor $Y$ são: taxa de juros Selic, produção industrial geral, crédito ao setor privado, agregado monetário M1, taxa de câmbio, expectativas de inflação, taxa swap e um índice de commodities. A escolha das variáveis se baseou em trabalhos clássicos da área da política mone-

5 O efeito Fisher visa mostrar que a taxa de juros nominal da economia é a soma da taxa de juros real e da taxa de inflação esperada. Assim, a taxa de juros nominal deve mudar sempre que houver alterações na taxa de juros real ou nas expectativas de inflação (MISHKIN, 2009). 
tária, como o de Sims (1992), e em trabalhos mais recentes voltados à economia brasileira, como, por exemplo, os de Minella (2003) e Tomazzia e Meurer (2009).

Com respeito ao número de defasagens, a escolha se baseou em critérios de seleção. Segundo Lutkepöhl (2005), esses métodos procuram obter o equilíbrio entre o ajuste do modelo e o número de parâmetros estimados. Por questões de parcimônia, escolheu-se o critério de seleção bayesiano de Schwartz (BIC).

Outra questão importante analisada no contexto de séries temporais é a da estacionariedade. Com respeito a esse ponto, o presente trabalho se baseou na abordagem de Toda e Yamamoto (1995). Segundo os autores, é possível trabalhar com um modelo VAR em nível com consistência, mesmo que as ordens de integração e cointegração das variáveis do modelo sejam incertas. Torna-se necessário, para isso, acrescer um número de defasagens igual à ordem máxima de integração das variáveis à quantidade de defasagens sugeridas pelo critério de informação. Por exemplo, se as variáveis do modelo são I(1), e o critério de informação bayesiano sugere o uso de uma defasagem, deve-se estimar o modelo econométrico com duas defasagens.

Para Toda e Yamamoto (1995), a escolha de se trabalhar com variáveis em nível é interessante porque evita a perda de informações incorrida pela diferenciação das variáveis. ${ }^{6}$ Em adição, os testes de raiz unitária podem se mostrar imprecisos frente à hipótese de as variáveis serem estacionárias com tendência. Além do mais, é difícil se saber, a priori, se as variáveis serão estacionárias com tendência, integradas, ou qual a ordem de integração.

Da mesma forma, Sims, Stock e Watson (1990) demonstram que modelos autorregressivos podem ser utilizados em nível sem que haja a necessidade de diferenciação das variáveis, dado que os resultados do modelo são consistentes com o aumento da amostra. Por essa razão, como argumentam Tomazzia e Meurer (2009), a escolha pelo modelo com variáveis em nível tem sido aplicada por diferentes autores no estudo da política monetária. ${ }^{7}$

Ainda assim, são realizados nesta pesquisa testes de raízes unitárias para se verificar a ordem de integração das séries econômicas utilizadas na estimação do modelo VAR, auxiliando a escolha do número de defasagens. Os testes realizados são o de Dickey-Fuller aumentado (ADF) e o KPSS.

As funções impulso-resposta do VAR (FIR) são utilizadas para a comparação do desempenho dos regimes de âncora cambial e de metas para inflação. Através

6 De acordo com os autores, a escolha pelo modelo VAR em nível decorre do problema do "viés do pré-teste”, isto é, os pré-testes, para detectar a presença de raiz unitária e cointegração nas séries, podem apresentar um baixo poder frente à hipótese alternativa de estacionariedade com tendência ou da ocorrência de quebras estruturais. Entretanto, Toda e Yamamoto (1995) pontuam que a utilização do método por eles proposto pode ser ineficiente no caso do modelo VAR possuir muitas variáveis.

7 Ver, por exemplo, Céspedes, Lima e Maka (2008) e Bernanke e Gertler (1995). 
dessa abordagem, é possível analisar o impacto das ações da política monetária por meio da taxa de juros, sobre a inflação e o produto da economia. Adicionalmente, a técnica de decomposição da variância é utilizada para associar as mudanças nos agregados relevantes (produto e inflação) aos choques nos instrumentos em cada regime. Para a obtenção das FIRs e da decomposição da variância, utilizou-se a matriz de decomposição de Cholesky. Primeiramente, adotam-se as variações na produção industrial como variável mais exógena. Tal escolha decorre do fato de que os hiatos do produto tendem a ser o elemento que direciona as expectativas inflacionárias e a própria inflação nos modelos monetários mais modernos (CLARIDA; GALÍ; GERTLER, 1999). Com essa mesma intuição, incluem-se, em seguida, as variáveis expectativas de inflação e a própria taxa de inflação. Ao admitir uma política monetária do tipo regra de Taylor, a taxa de juros entra, em seguida, respondendo às variações no produto, nas expectativas e na inflação. Alterações na taxa curta podem afetar toda a estrutura de juros e, por conseguinte, a taxa de longo prazo. A política monetária impacta, ainda, a liquidez bancária. Assim, após a taxa de juros de longo prazo, incluem-se medidas do agregado monetário e das operações de crédito ao setor privado (aqui, a política monetária pode afetar o crédito). Por fim, inclui-se a taxa de câmbio, assumindo-se que responde rápida e dinamicamente aos desdobramentos do sistema econômico como um todo ordenações similares foram observadas nos estudos de Christiano, Eichenbaum e Evans (1999), Minella (2003) e Tomazzia e Meurer (2009).

Assim, especificamente no regime de âncora cambial, segue-se a seguinte ordenação: produção industrial, índice de preço de commodities - proxy para expectativas (SIMS, 1992) -, taxa de inflação, taxa de juros básica Selic, agregado monetário M1, operações de crédito ao setor privado e taxa de câmbio real. No regime de metas para inflação, a ordenação é dada por: produção industrial, expectativas de inflação, taxa de inflação, taxa de juros básica Selic, taxa de juros de longo prazo representada pelo Swap, agregado monetário M1, operações de crédito ao setor privado e taxa de câmbio nominal. ${ }^{8}$

\subsection{Tratamentos e Base de Dados}

Os dados utilizados têm periodicidade mensal, variando de janeiro de 1995 até dezembro de 2014, ou seja, um total de 240 observações. Como instrumento de política monetária do $\mathrm{BCB}$, utilizou-se a Selic. Para o produto, considerou-se a produção industrial, que é disponibilizada pelo IBGE. ${ }^{9}$ Para a taxa de câmbio, foi

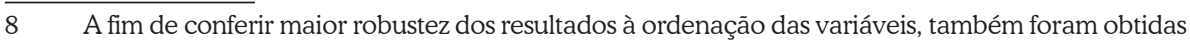
funções impulso-resposta generalizadas. As informações e conclusões de políticas listadas a seguir não sofrem alterações significativas.

9 Instituto Brasileiro de Geografia e Estatística (IBGE). Pesquisa Industrial Mensal - Produção Física PIM-PF. Rio de Janeiro: IBGE, de 1995 a 2014. Acesso em: 10 de junho de 2016. É válido destacar 
utilizada a taxa de câmbio R \$/US\$ - compra/venda, calculada pelo BCB. Para a taxa de inflação, foi empregado o IPCA, disponibilizado pelo IBGE. Para o agregado monetário, adotou-se o M1, que representa a base monetária e os meios de pagamento calculados pelo BCB. Para o agregado de crédito, foram escolhidas as operações de crédito ao setor privado, calculado pelo BCB. Os dados de expectativa de inflação foram elaborados com base no boletim Focus do BCB e no índice de preços das commodities gerais, disponibilizado na Federal Reserve Economic Data (Fred) database ${ }^{10}$. Para a taxa de juros de longo prazo, empregou-se a taxa referencial Swaps-DI pré-fixada, que é disponibilizada pela BMËF Bovespa. ${ }^{11}$

Cabe destacar que houve a necessidade de adaptar o modelo empírico do câmbio administrado em razão da indisponibilidade de alguns dados. Por exemplo, não foi possível incluir a variável Swap, já que seus dados são publicados somente a partir de 1999. Da mesma maneira, a variável expectativa de inflação é mensurada a partir de 2001. Com base no trabalho de Sims (1992), utilizou-se como proxy para a última variável um índice de preços de commodities.

Sims (1992) argumenta que o preço das commodities é um indicador de inflação futura para o banco central, uma vez que diversos produtos, como petróleo, gás e grãos, são incluídos nessa variável. Uma alta nos preços desses bens sugere elevação futura nos custos produtivos e na inflação. Contudo, a correlação temporal da Lprices e das expectativas de inflação (EI) no período sobreposto não é boa. De fato, incluir uma proxy para expectativas foi uma tarefa bastante complexa na amostra do regime cambial. Outros sinalizadores foram testados, como a inflação norte-americana e as variações nas reservas. Os resultados não ficaram melhores do que aqueles apresentados na próxima seção. Inclusive, as FIRs são mantidas se a série de commodities é excluída das regressões. Por isso, preferiu-se manter a regressão no formato sugerido por Sims (1992). No entanto, a obtenção de uma proxy para as expectativas inflacionárias no regime de câmbio administrado parece ser uma boa linha para pesquisas futuras. Quanto ao tratamento dos dados, as séries foram, quando necessário, logaritmizadas, dessazonalizadas e deflacionadas. A Tabela 1 descreve as variáveis em detalhes.

que a produção geral da indústria é um dos componentes do Indicador Coincidente Composto da Economia (ICCE), calculado pelo Instituto Brasileiro de Economia da Fundação Getúlio Vargas (Ibre/FGV), que mede as condições econômicas atuais e a intensidade da atividade econômica em bases mensais. Isso reforça sua inclusão como um indicador da atividade econômica geral, disponível em base mensal para todo o período. Ainda assim, especificações alternativas também consideraram o indicador do PIB mensal calculado pelo BCB. Tal como no exercício de robustez anterior, os resultados centrais da pesquisa mantiveram-se válidos com essa variável.

10 Fundo Monetário Internacional (FMI). Global Price Index of All Commodities [PALLFNFINDEXQ], obtido em FRED, Federal Reserve Bank of St. Louis. Disponivel em: < https://fred.stlouisfed. org/series/pallfnfindexq > . Acesso em: 10 jun. 2016.

11 Bolsa de Valores, Mercadorias e Futuros (BMEFFBovespa). Taxa referencial - swaps - DI pré-fixada 360 dias - fim de período - (\% a.a.) [BMF12_SWAPDI360F12], obtido em Ipeadata. Disponível em: $<$ http://www.ipeadata.gov.br/Default.aspx> $>$. Acesso em: 10 jun. 2016. 
Tabela 1 - Descrição das variáveis utilizadas

Variáveis Descrição dos dados

Fonte

Sinal esperado

de uma respos-

ta à Selic

\begin{tabular}{|c|c|c|c|}
\hline \multicolumn{4}{|c|}{ MODELO EMPÍRICO - ÂNCORA CAMBIAL } \\
\hline SELIC & Taxa básica de juros: Over/Selic (\% a.m.) & Ipeadata & \\
\hline LPIG & $\begin{array}{l}\text { Produção industrial geral: índice dessa- } \\
\text { zonalizado (média } 2002=100 \text { ). }\end{array}$ & IBGE/PIM-PF & Negativo \\
\hline IPCA & $\begin{array}{l}\text { Índice de preços ao consumidor amplo } \\
\text { calculado pelo IBGE (\% a.m.). }\end{array}$ & Ipeadata & Negativo \\
\hline LM1 & Agregado monetário M1. & $\mathrm{BCB}$ & Negativo \\
\hline LOCSP & Operações de crédito ao setor privado. & $\mathrm{BCB}$ & Negativo \\
\hline LCAMR & $\begin{array}{l}\text { Taxa de câmbio nominal (R } \$ / \mathrm{US} \$ \text { - co- } \\
\text { mercial): venda deflacionada pelo IPCA. }\end{array}$ & $\mathrm{BCB}$ & $\begin{array}{l}\text { Valorização } \\
\text { cambial }\end{array}$ \\
\hline LPRICES & Índice de preço de commodities. & $\begin{array}{l}\text { Fred } \\
\text { database }\end{array}$ & $\begin{array}{l}\text { Não determina- } \\
\text { do a priori. }\end{array}$ \\
\hline \multicolumn{4}{|c|}{ MODELO EMPÍRICO - METAS PARA INFLAÇÃO } \\
\hline SELIC & Taxa básica de juros: Over/Selic (\% a.m.) & Ipeadata & \\
\hline LPIG & $\begin{array}{l}\text { Produção industrial geral: índice (média } \\
2002=100 \text { ) }\end{array}$ & IBGE/PIM-PF & Negativo \\
\hline IPCA & $\begin{array}{l}\text { Índice de preços ao consumidor amplo } \\
\text { calculado pelo IBGE (\% a.m.). }\end{array}$ & Ipeadata & Negativo \\
\hline LM1 & Agregado monetário M1. & $\mathrm{BCB}$ & Negativo \\
\hline LOCSP & Operações de crédito ao setor privado. & $\mathrm{BCB}$ & Negativo \\
\hline LCAM & $\begin{array}{l}\text { Taxa de câmbio nominal (R\$/US\$): } \\
\text { comercial-venda. }\end{array}$ & $\mathrm{BCB}$ & $\begin{array}{l}\text { Valorização } \\
\text { cambial }\end{array}$ \\
\hline EI & $\begin{array}{l}\text { Expectativa de inflação do final do mês } \\
\text { seguinte no início do mês corrente } \\
\text { (a.m.\%). }\end{array}$ & $\begin{array}{l}\text { Elaborado } \\
\text { com base no } \\
\text { BCB/Focus. }\end{array}$ & Negativo \\
\hline SWAP & $\begin{array}{l}\text { Taxa de juros de longo prazo. Taxa re- } \\
\text { ferencial swaps-DI pré-fixada: } 360 \text { dias } \\
\text { - fim de período (\% a.a.). }\end{array}$ & BMEFF & $\begin{array}{l}\text { Não determina- } \\
\text { do a priori. }\end{array}$ \\
\hline
\end{tabular}

Fonte: Elaboração própria.

\section{Resultados}

A análise dos resultados se inicia com as informações contidas na Tabela 2, que traz estatísticas descritivas referentes ao produto, inflação e taxa de juros para os regimes de âncora cambial e de metas para inflação. 
Tabela 2 - Estatísticas descritivas

\begin{tabular}{lcccc}
\hline & \multicolumn{2}{c}{ Âncora cambial } & \multicolumn{2}{c}{ Metas para inflação } \\
\hline Variável & Média & DP & Média & DP \\
\hline Crescimento da PIG & 1,51 & 7,06 & 2,17 & 5,80 \\
Inflação & 9,67 & 9,49 & 6,63 & 5,26 \\
Taxa Selic & 33,52 & 13,23 & 14,00 & 4,88 \\
\hline
\end{tabular}

Fonte: Elaboração própria.

Notas: DP é o desvio padrão; PIG refere-se à produção industrial geral; as taxas de crescimento da PIG estão em termos de seu valor em um respectivo mês em comparação com o mesmo mês do ano anterior; a inflação (IPCA) e a taxa Selic estão anualizadas.

Percebe-se que, no regime de metas, a média e a volatilidade da inflação se reduziram. Resultados similares foram encontrados para a taxa de juros básica Selic.

A Tabela 2 pode sugerir que a proposição de Friedman (1977), de que inflação alta é sinônima de inflação volátil, é uma realidade para o Brasil. Segundo o autor, em ambientes de baixa inflação os agentes econômicos têm maior estabilidade para extrair os sinais relevantes dos níveis agregados de preços e têm, portanto, maior facilidade para precificar seus produtos relativamente aos demais bens e serviços da economia. Consequentemente, a volatilidade da inflação também é baixa. Contudo, em cenários de alta inflação, os sinais fornecidos pela economia são prejudicados. Além disso, haverá maior incerteza a respeito do comprometimento por parte da autoridade monetária em suportar os custos da desinflação. Assim, a base para a tomada de decisão fica fragilizada e a volatilidade da inflação tende a se elevar.

Com a adoção do regime de metas, espera-se que a incerteza inflacionária seja reduzida, isto é, ao passo que uma meta de inflação baixa é divulgada (e, principalmente, atingida) pelo banco central, os agentes econômicos têm um ambiente macroeconômico mais previsível para a formação de preços na economia, reduzindo sua média e variância.

Com respeito ao produto, verifica-se que, para o regime de metas para inflação, a sua média de crescimento foi maior e, além disso, houve redução de sua volatilidade quando comparada ao regime de âncora cambial. Esse é um importante resultado, pois, segundo Alesina e Summers (1993), bancos centrais mais independentes e que presam pela luta contra a inflação não necessariamente produziram aumentos excessivos na volatilidade do produto. Dessa maneira, o regime de metas para inflação, cuja institucionalização se baseou na premissa de que os bancos centrais deveriam ser mais independentes e responsáveis pela estabilidade de preços, mostra indícios, como visto na Tabela 2, de não ter causado impactos negativos na taxa de crescimento e na volatilidade da produção do Brasil. Pelo 
contrário, como defendido por Friedman (1977), as taxas de inflação mais baixas e estáveis podem estar contribuindo para o processo de crescimento econômico (via efeitos preços relativos e taxas de juros estáveis, que aumentam a eficiência da alocação dos recursos intra e intertemporalmente).

Ressalta-se, como relatado em seções anteriores, que o Brasil, em sua experiência no regime de âncora cambial, foi afetado por choques externos que causaram significativos impactos macroeconômicos. Assim, para aprofundar a análise das hipóteses do trabalho e para que se tenham melhores indicações quanto à eficácia do controle da política monetária em ambos os regimes, apresentam-se, na sequência, os resultados advindos dos modelos VAR estimados.

Primeiramente, realizaram-se os testes de raiz unitária ADF e KPSS para verificar se as séries são estacionárias e suas respectivas ordens de integração. Essas informações são úteis para determinar corretamente o número de defasagens necessárias para estimar os parâmetros do VAR de forma consistente (TODA; YAMAMOTO, 1995). A tabela apresentada no Apêndice A sumariza os resultados.

As evidências desses testes permitem concluir que não é possível rejeitar a hipótese nula de raiz unitária em nível para quase todas as variáveis no $\mathrm{ADF}$, com exceção do IPCA, no regime de metas. Ademais, todas as variáveis de uma maneira geral se mostraram estacionárias em primeira diferença, isto é, sendo I(1). Assim, a metodologia de Toda e Yamamoto (1995) sugere adicionar uma defasagem ao número obtido por critérios de informação a fim de se obter estimativas consistentes dos parâmetros com o método VAR.

Com esse propósito, estimou-se o número ótimo de defasagens pelo critério bayesiano de Schwarz (BIC), que indicou a inclusão de uma defasagem. Dessa forma, destaca-se que o modelo VAR abordado neste estudo apresentou, ao final, duas defasagens, uma devido ao número ótimo, segundo o critério de informação, mais o lag adicionado, em função da ordem máxima de integração das variáveis. É pertinente ressaltar que esse critério tem sido bastante utilizado pelo BCB em seus modelos VAR para a tomada de decisões - ver, a esse respeito, o Relatório de Inflação do segundo trimestre de 2004 (BANCO CENTRAL DO BRASIL, 2004). Ademais, após sua estimação, percebeu-se que os inversos de todas as raízes se encontraram dentro do círculo unitário, atestando-se pela estabilidade dos modelos estimados.

Assim, nas Figuras 1 e 2, são apresentados os resultados das funções impulsoresposta para o regime de âncora cambial e de metas para inflação. Sobre as principais evidências, cabe destacar primeiramente que os efeitos da taxa de juros sobre o M1 e as operações de crédito em ambos os contextos se deram conforme o esperado pela teoria, havendo apenas diferenças na magnitude da resposta. 
Figura 1 - Funções impulso-resposta 1995/01 a 1999/06: regime de âncora cambial

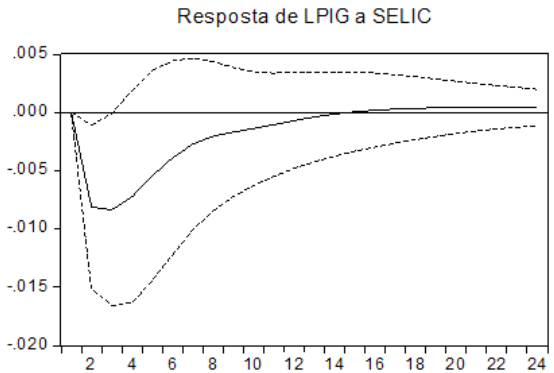

Resposta de LM1 a SELIC

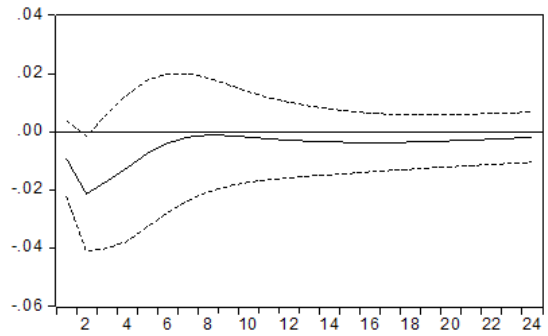

Resposta de IPCA a SELIC

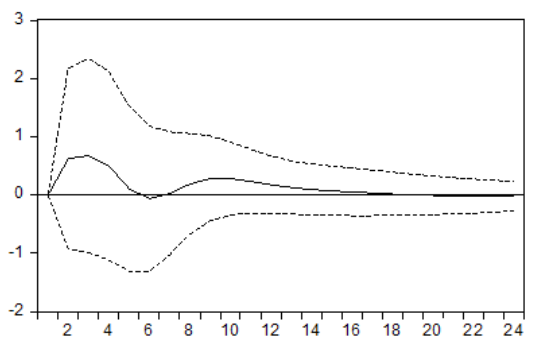

Resposta de LCAMR a SELIC

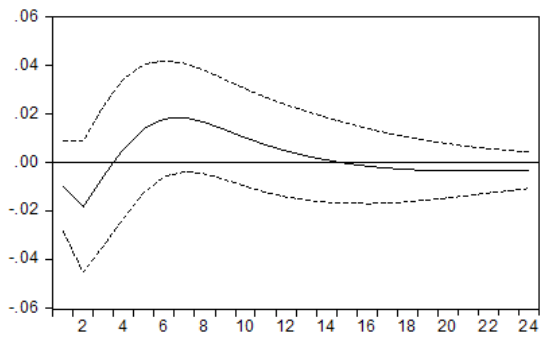

Fonte: Elaboração própria.

Para as demais variáveis, as diferenças são mais acentuadas, conforme fica explícito a seguir. No regime de âncora, percebe-se que um choque da política monetária (aumento nos juros) na magnitude de um ponto percentual (p.p.) provoca retração de $-0,8 \%$ do produto nos primeiros dois meses. A recuperação da produção acontece lentamente e somente a partir do quarto mês.

Em contrapartida, não foi possível descartar a hipótese de que a política monetária não teve efeitos sobre o nível de preços da economia durante o regime cambial. Os resultados mostram que nesse período os choques na taxa de juros obtiveram relação estatisticamente não significativa com a inflação. Para verificar se essa resposta é decorrente de má especificação do modelo, foram adicionadas variáveis como o volume de reservas internacionais e a dívida pública, conforme sugerem Mello e Moccero (2011). ${ }^{12}$ No entanto, as FIRs obtidas não foram dife-

12 A variável fiscal utilizada, em função de sua disponibilidade, foi a dívida líquida do setor público. Ela foi posicionada antes do indicador de expectativas, assumindo que a posição fiscal afeta as expectativas e a inflação no país. As reservas são inseridas antes da taxa de câmbio, uma vez que a posição de liquidez internacional do governo brasileiro afetava as expectativas e as movimentações nos mercados cambiais. Os testes sugerem que ambas as variáveis são I(1) e que o critério BIC selecionou uma defasagem. Assim, estimou-se uma VAR(2) para o modelo, que inclui a dívida e as reservas internacionais. 
rentes das apresentadas na Figura 1. Com efeito, esse resultado pode realmente sugerir que a política monetária sobre o regime de câmbio administrado não era capaz de afetar significativamente a taxa de inflação da economia.

Por outro lado, no regime de metas para inflação (ver Figura 2), percebe-se que o impacto de uma política monetária contracionista sobre o produto é particularmente inferior quando comparada ao regime de câmbio administrado. Os resultados indicam que o efeito recessivo sobre a produção se situa próximo a $-0,1 \%$ em dois meses, com uma recuperação se iniciando no quinto mês.

Outro resultado que desperta atenção é a resposta da inflação ao choque monetário nesse regime. Encontrou-se que, após um choque de mesma magnitude na taxa de juros, a inflação se reduz em -0,7 p.p. nos quatro primeiros meses, estabilizando-se nos meses em seguida. Em outras palavras, é possível inferir que a política monetária no regime de metas obteve relativo êxito no combate às variações dos preços.

Certamente, parte desse resultado pode estar atrelada à resposta das expectativas de inflação aos choques na taxa de juros. Foi possível constatar que, durante o período de vigência do regime de metas, choques de política monetária conseguiram reduzir as expectativas dos agentes quanto à inflação futura. Resultado semelhante foi obtido por Minella (2003), que encontra evidências empíricas nesse sentido.

Quanto à taxa de juros de longo prazo, verifica-se que a resposta ao aperto monetário pode ser explicada pela estrutura a termo das taxas de juros. ${ }^{13} \mathrm{O}$ raciocínio por trás desse mecanismo é simples: quando o banco central eleva a taxa básica de juros de curto prazo, os agentes econômicos esperam que no futuro a taxa nominal de curto prazo caia (dada a redução das expectativas inflacionárias e o efeito Fisher). Assim, é natural que as taxas de juros de longo prazo se reduzam em função do choque. Portanto, há indícios de que a redução das taxas de juros de longo prazo passa pelo controle consistente da inflação pelo BCB.

13 Nesse cenário, a taxa de juros de longo prazo corresponde a uma média das taxas de juros esperadas de curto prazo ao longo do tempo. 
Figura 2 - Funções impulso-resposta 1999/07 a 2014/12: regime de metas para inflação
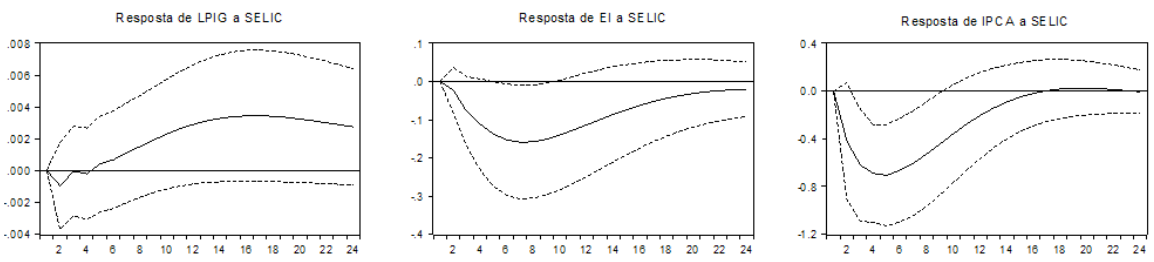

Resposta de SWAP a SELIC
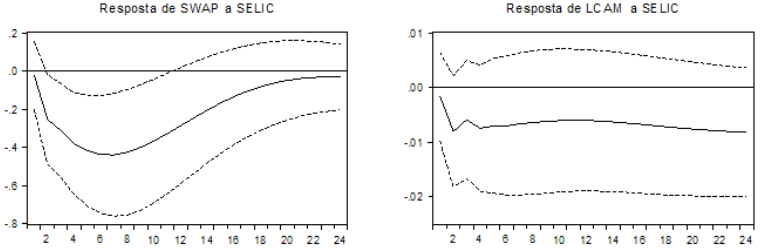

Fonte: Elaboração própria.

Por fim, ainda pode-se reportar que, no regime de metas para inflação, o crédito ao setor privado sofreu respostas significativas quanto à variação da taxa de juros, apresentando o efeito mínimo de $-0,3 \%$ nos primeiros dois meses. No regime de âncora cambial, por sua vez, não se verificou relação significativa entre taxa de juros e essa variável.

Em resumo, os resultados encontrados nesta pesquisa evidenciam que a política monetária tem exercido menor impacto sobre a produção da economia e controlado mais diretamente os níveis de preços. Para se obter mais indicativos de que a política monetária tem mostrado desempenho melhor no regime de metas inflacionárias, em comparação com o período de câmbio controlado, apresenta-se a decomposição da variância do erro de previsão do produto e da inflação nas Tabelas 3 e 4. 
Tabela 3 - Análise da decomposição da variância do erro de previsão: âncora cambial

\begin{tabular}{|c|c|c|c|c|c|c|c|c|}
\hline \multicolumn{9}{|c|}{ Decomposição da variância do erro de previsão da PIG } \\
\hline Período & $\mathrm{DP}$ & LPIG & LPRICES & IPCA & SELIC & LM1 & LOCSP & LCAMR \\
\hline 1 & 0,02 & 100,00 & 0,00 & 0,00 & 0,00 & 0,00 & 0,00 & 0,00 \\
\hline 5 & 0,04 & 76,59 & 0,61 & 5,33 & 15,74 & 0,03 & 0,38 & 1,32 \\
\hline 10 & 0,04 & 72,66 & 1,83 & 5,02 & 16,51 & 0,83 & 0,48 & 2,67 \\
\hline \multicolumn{9}{|c|}{ Decomposição da variância do erro de previsão da inflação } \\
\hline Período & $\mathrm{DP}$ & LPIG & LPRICES & IPCA & SELIC & LM1 & LOCSP & LCAMR \\
\hline 1 & 0,02 & 0,55 & 2,14 & 97,32 & 0,00 & 0,00 & 0,00 & 0,00 \\
\hline 5 & 0,05 & 0,87 & 2,59 & 70,44 & 2,65 & 3,74 & 1,37 & 18,34 \\
\hline 10 & 0,08 & 2,64 & 3,06 & 66,66 & 2,95 & 4,51 & 2,53 & 17,64 \\
\hline
\end{tabular}

Fonte: Elaboração própria.

Nota: DP é o desvio padrão.

Tabela 4 - Análise da decomposição da variância: metas para inflação

\begin{tabular}{cccccccccc}
\hline \multicolumn{8}{c}{ Decomposição da variância do erro de previsão da PIG } \\
\hline Período & DP & LPIG & EI & IPCA & SELIC & SWAP & LM1 & LOCSP & LCAM \\
\hline 1 & 0,02 & 100,00 & 0,00 & 0,00 & 0,00 & 0,00 & 0,00 & 0,00 & 0,00 \\
5 & 0,03 & 86,15 & 2,89 & 0,03 & 0,13 & 3,32 & 1,42 & 0,16 & 5,92 \\
10 & 0,04 & 59,08 & 6,46 & 1,23 & 1,03 & 19,68 & 7,63 & 0,59 & 4,31 \\
\hline
\end{tabular}

Decomposição da variância do erro de previsão da inflação

\begin{tabular}{cccccccccc}
\hline Período & DP & LPIG & EI & IPCA & SELIC & SWAP & LM1 & LOCSP & LCAM \\
\hline 1 & 0,37 & 0,65 & 4,72 & 94,62 & 0,00 & 0,00 & 0,00 & 0,00 & 0,00 \\
5 & 1,15 & 2,00 & 8,26 & 60,47 & 7,45 & 18,98 & 0,26 & 1,20 & 1,38 \\
10 & 1,51 & 3,06 & 10,14 & 45,41 & 10,29 & 27,27 & 0,35 & 1,00 & 2,48 \\
\hline
\end{tabular}

Fonte: Elaboração própria.

Nota: DP é o desvio padrão.

Para o regime de âncora cambial, percebe-se que a variância do erro de previsão da produção é mais bem explicada, excetuando-se seus próprios choques, pelas perturbações da taxa de juros. Possivelmente, esse resultado se deve ao fato de que, no regime de câmbio fixo, a taxa de juros passou a ser o principal amortecedor dos choques externos, os quais foram numerosos entre 1994 e 1999. Assim, a autoridade monetária respondia com elevações acentuadas das taxas de juros, o que gerava fortes oscilações da produção.

Para a taxa de inflação, os resultados mostram que, além dos choques advindos da própria variável, a taxa de câmbio real tem o segundo maior poder de 
explicação do erro de previsão. Esse panorama mostra que a política monetária, via taxa de juros, foi realmente secundária nesse período. A inflação tinha, praticamente, vida própria. Em curto prazo, mais de $70 \%$ de sua volatilidade era oriunda de suas movimentações passadas. Além disso, as expectativas de desvalorização cambial e de maior inflação forçavam a alta dos juros pelo BCB. Nesse sentido, pode-se inferir que a adoção do regime de metas para a inflação proporcionou maior autonomia para a política monetária no Brasil.

No regime de metas (ver Tabela 4), observa-se que a taxa de juros de longo prazo foi a variável de maior importância sobre a variância do erro de previsão do PIB, com poder de explicação de cerca de $20 \%$. Esse resultado pode sugerir, portanto, que sob esse regime a taxa de juros de curto prazo, como instrumento de política monetária, está de fato sendo relevante para a economia brasileira, vista sua estreita relação com a taxa de longo prazo.

Com relação à inflação, constatou-se que as variáveis que melhor explicam a variância do seu erro de previsão são as expectativas de inflação, a taxa de juros Selic e a taxa de juros de longo prazo. Especificamente, os dados sugerem que a eficácia da política monetária sobre o regime de metas para inflação também depende de sua capacidade de controlar as expectativas, o que, segundo Pastore (2015), é o elemento que de fato estabiliza o nível de preços. De modo geral, isso evidencia que a política monetária sobre o regime de metas para inflação tem sido eficaz em afetar negativamente a inflação tanto instantaneamente, quanto através das expectativas e da taxa Swap, a qual sinaliza a posição futura esperada da política monetária.

Com o objetivo de aproximar a precisão estatística dos modelos econométricos utilizados no presente trabalho, dividiu-se o período referente ao regime de metas para inflação em intervalos menores. Esse procedimento é interessante uma vez que permite nivelar o tamanho das amostras do período do sistema de metas para inflação à amostra do sistema de âncora cambial. Além disso, torna-se possível analisar o efeito da política monetária em três importantes momentos da economia brasileira.

No primeiro período, que varia de julho de 1999 a dezembro de 2004, caracteriza-se o início do regime de metas e a incerteza do mercado com relação à possibilidade de alterações bruscas na condução da política econômica. No segundo período, fizeram parte dados de janeiro de 2004 a dezembro de 2009, período marcado por um momento econômico relativamente favorável para a economia brasileira, com crescimento do produto e menor desconfiança sobre os rumos da política econômica adotada. Ademais, o controle da política monetária foi feito mais de perto pelo $\mathrm{BCB}$, por meio do chamado tripé macroeconômico. No terceiro período, avaliam-se informações datadas de janeiro de 2010 até o fim de 2014, 
época em que se observou uma política de expansão fiscal, denotada posteriormente por "Nova Matriz Econômica" (PASTORE, 2015).

Com respeito à produção industrial, a Figura 3 (parte $a$ ) mostra que os efeitos recessivos gerados por uma contração da liquidez são mais visíveis na segunda amostra. Além disso, os intervalos dois desvios padrões da primeira e da terceira amostra incluem o zero em todas as defasagens, isto é, a resposta da produção aos juros nesses períodos pode ser não significativa. Assim, a capacidade do BCB de afetar a demanda agregada e a produção como um todo, com vistas a controlar a inflação, foi maior no período em entre janeiro de 2004 e dezembro de 2009.

Figura 3 - Resposta da produção, inflação e expectativas ao choque na taxa Selic
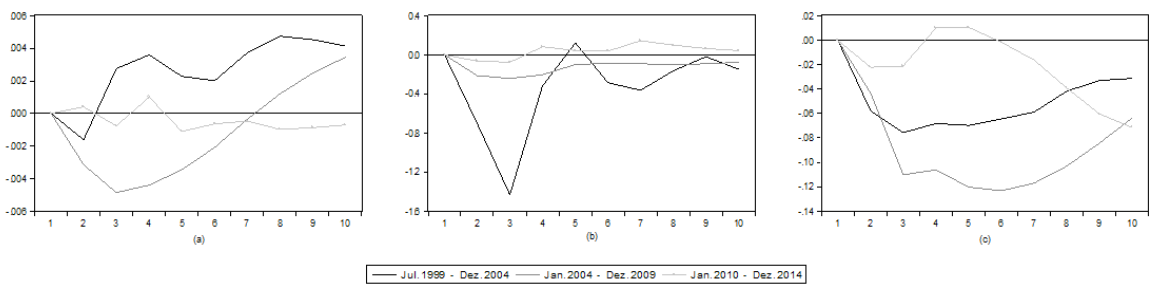

Fonte: Elaboração própria.

Nota: Parte $a$ : PIG; parte $b$ : inflação (IPCA); parte $c$ : expectativas.

A inflação respondeu negativamente aos juros nos dois primeiros períodos, como pode ser visto na parte $b$ da Figura 3. Entre 1999 e 2003, a redução dos preços era mais intensa em curto prazo com uma dissipação mais rápida. Na segunda amostra, a resposta da inflação é menor em curto prazo, porém os efeitos da taxa de juros sobre a queda dos preços são mais duradouros (o efeito acumulado, dez períodos após o choque, foi maior na primeira amostra). Na amostra entre 2010 e 2014, há indícios de que o BCB perdeu controle das variações na taxa de inflação. A resposta dessa variável aos choques nos juros foi pequena e positiva, em termos acumulados.

Quanto às expectativas, percebe-se que juros maiores proporcionaram uma redução mais intensa dessa variável na segunda amostra, em comparação com a primeira. Como o regime de metas ainda era recente entre 1999 e 2003, esse é um resultado esperado. Com o tempo, o público passou a entender melhor o esquema de funcionamento do sistema de metas e as ações do BCB ganharam mais credibilidade. Na terceira amostra, a resposta das expectativas aos choques nos juros fica incerta, oscilando ao longo de zero. ${ }^{14}$ Esse resultado é corroborado pelo fato de

14 Na Figura 3(parte c), os efeitos dos juros sobre as expectativas no terceiro período são visualmente maiores do que os obtidos na primeira amostra, após oito meses. Contudo, ressalta-se que, entre 1999 e 2004, as variações nas expectativas foram estatisticamente significativas, ao passo que, entre 2010 e 2014, os intervalos de confiança incluíram o valor zero em todas as defasagens. 
que as expectativas inflacionárias divergiram gradativamente do centro da meta nos últimos anos desta pesquisa.

Em suma, a divisão do período pós-regime de metas para a inflação elucida o fato de que a política monetária perdeu poder de ancorar a atividade econômica no Brasil nos anos mais recentes da amostra. As evidências encontradas sugerem que a produção industrial, a inflação e as expectativas responderam com menor intensidade à política de juros do BCB desde 2010. Assim, a reorientação da política macroeconômica no país prejudicou o desempenho das ações do $\mathrm{BCB}$, implicando taxas crescentes de inflação, que alcançaram os valores de 10,7\%, em 2015, e 6,3\%, em 2016.

\section{Considerações Finais}

O presente trabalho teve como objetivo comparar o desempenho macroeconômico dos regimes monetários implementados desde o início do Plano Real no Brasil, quais sejam, o regime de âncora cambial e o regime de metas para inflação. Para tanto, utilizou-se a metodologia VAR para se verificar em qual dos dois períodos a estabilização da economia foi mais eficaz, principalmente com respeito às variações da taxa de inflação e do produto.

Os resultados indicaram que, sob o regime de âncora cambial, a política monetária não foi capaz de controlar adequadamente o seu principal indicador de inflação (IPCA), que era altamente determinado por suas próprias variações e pelas alterações do câmbio real. Assim, os choques nos juros surtiam efeito mínimo sobre os preços e impactos altamente recessivos sobre o produto.

Para o regime de metas para inflação, verificaram-se reduções na volatilidade da inflação, dos juros e do produto industrial quando comparado ao regime de âncora cambial. Ademais, no período do regime de metas, observou-se significativa influência da taxa básica sobre o produto, as expectativas e a inflação propriamente dita. Resultados semelhantes foram encontrados por Minella et al. (2003), Mello e Moccero (2011) e Mendonça, Medrano e Sachsida (2010).

As análises em diferentes amostras mostraram, contudo, uma perda de eficácia da política monetária entre os anos de 2010 e 2014, quando as alterações nos juros não afetaram significativamente a inflação e as expectativas. Nesse mesmo período, houve um distanciamento das taxas de inflação e das expectativas inflacionárias do centro da meta. Conclui-se, portanto, que a simples adoção do regime de metas não é garantia de bom desempenho da política monetária. A capacidade de ajustar a economia dentro dessa abordagem depende crucialmente do grau de comprometimento do $\mathrm{BCB}$ e, possivelmente, do governo brasileiro como um todo, com as políticas que fundamentam o regime de metas para a inflação. 


\section{Referências}

ALESINA, A.; SUMMERS, L. Central bank independence and macroeconomic performance: some comparative evidence. Journal of Money, Credit and Banking, Columbus, v. 25, n. 2, p. 151-162, 1993.

ALMEIDA, A.; GOODHART, C. Does the adoption of inflation targets affect central bank behavior? London School of Economics, 1998. Trabalho não publicado.

ARESTIS, P.; PAULA, L. F.; FERRARI-FILHO, F. A nova política monetária: uma análise do regime de metas de inflação no Brasil. Revista Economia e Sociedade, Campinas, v. 18, n. 1, p. 1-30, 2009.

ARQUETE, L.; JAYME JÚNIOR, F. Política monetária, preços e produto no Brasil (19942002): uma aplicação de vetores auto-regressivos. In: ENCONTRO NACIONAL DE ECONOMIA, 31., 2003, Porto Seguro. Anais.... Porto Seguro: ANPEC, 2003.

BANCO CENTRAL DO BRASIL. Regime de metas para a inflação no Brasil. Brasília, DF: BCB, 2015. (Série "Perguntas Mais Frequentes").

BARBOSA, N. Inflation targeting in Brazil: 1999-2006. International Review of Applied Economics, London, v. 22, n. 2, p.187-200, 2008.

BERNANKE, B.; et al. Inflation targeting lessons from the international experience. Princeton: Princeton University Press, 2001.

BERNANKE, B.; GERTLER, M. Inside the black box: the credit channel of monetary policy transmission. Journal of Economic Perspectives, Nashville, v. 9, n. 4, p.27-48, 1995.

BEZERRA, J. F.; LIMA, R. C.; SILVA, I. E. M. Estudo sobre o canal de crédito bancário no Brasil: abordagem por meio do matching das funções impulso resposta. Economia Aplicada, São Paulo, v. 20, n. 2, p. 245-264, 2016.

BUENO, R. Econometria de séries temporais. São Paulo: Cengage Learning, 2012.

CALVO, G.; MISHKIN, F. S. The mirage of exchange rate regimes for emerging markets countries. Journal of Economic Perspectives, Nashville, v. 17, n. 4, p. 99-118, 2003.

CARNEIRO, D. D.; SALLES, F. M.; WU, T. Juros, câmbio e as imperfeições do canal do crédito. Economia Aplicada, São Paulo, v. 10, n. 1, p. 7-23, 2006.

CÉSPEDES, B.; LIMA, E.; MAKA, A. Monetary policy, inflation and the level of economic activity in Brazil after the Real Plan: stylized facts from SVAR models. Revista Brasileira de Economia, Rio de Janeiro, v. 62, n. 2, p. 123-160, 2008.

CHRISTIANO, L. J.; EICHENBAUM, M.; EVANS, C. L. Monetary policy shocks: what have we learned and to what end? In: TAYLOR, J. B.; WOODFORD, M. (Ed.). Handbook of macroeconomics. Amsterdam: Elsevier Sci., 1999. v. 1A.

CLARIDA, R.; GALÍ, J.; GERTLER, M. The science of monetary policy: a new Keynesian perspective. Journal of Economic Literature, Nashville, v. 37, p. 1661-1707, 1999. 
CORREA, A. S.; MINELLA, A. Nonlinear mechanisms of the exchange rate pass-through: a Phillips curve model with threshold for Brazil. Revista Brasileira de Economia, Rio de Janeiro, v. 64, n. 3, p. 231-243, 2010.

DUTRA, L. D.; FEIJÓ, C. A.; BASTOS, J. C. A. Impacto de choques de política monetária sobre a oferta de crédito regional: uma análise econométrica a partir da metodologia VAR para o Brasil nos anos 2000. Brazilian Keynesian Review, Belo Horizonte, v. 3, n. 1, p. 48-74, 2017.

FRIEDMAN, M. Nobel lecture: inflation and unemployment. Journal of Political Economy, Chicago, v. 85, n. 3, p. 451-472, 1977.

GOLDFAJN, I.; MUINHOS, M. Metas para o regime de metas: completando a transição. In: GIAMBIAGI, F.; PORTO, C. (Ed.). 2022: propostas para um Brasil melhor no ano do bicentenário. Rio de Janeiro: Campus, 2011.

LIMA, A. M. C.; ISSLER, J. V. A hipótese das expectativas na estrutura a termo de juros no Brasil: uma aplicação de modelos de valor presente. Revista Brasileira de Economia, Rio de Janeiro, v. 57, n. 4, p. 873-898, 2003.

LOPES, L. S.; CHAUVET, M.; LIMA, J. E. The end of Brazilian big inflation: lessons to monetary policy from a standard New Keynesian model. Empirical Economics, Heidelberg, v. 55, n. 4, p. 1475-1505, 2018.

LUTKEPÖHL, H. New introduction to multiple time series. New York: Springer Verlag, 2005.

MARÇAL, E. F.; VALLS PEREIRA, P. L. V. A estrutura a termo das taxas de juros no brasil: testando a hipótese de expectativas. Pesquisa e Planejamento Econômico, Rio de Janeiro, v. 37, n. 1, p. 113-148, 2007.

MELLO, L.; MOCCERO, D. Monetary policy and macroeconomic Stability in Latin America: the cases of Brazil, Chile, Colombia and Mexico. Journal of International Money and Finance, Amsterdam, v. 30, p. 229-245, 2011.

MENDONÇA, H. F. Mecanismos de transmissão monetária e a determinação da taxa de juros: uma aplicação da regra de Taylor ao caso brasileiro. Economia e Sociedade, Campinas, v. 16, n. 1. p. 65-81, 2001.

MENDONÇA, J.; MEDRANO, J.; SACHSIDA, A. Efeitos da política monetária na economia brasileira: resultados de um procedimento de identificação agnóstica. Pesquisa e Planejamento Econômico, Rio de Janeiro, v. 40, n. 3, p. 367-394, 2010.

MINELLA, A. Monetary policy and inflation in Brazil (1975-2000): a VAR estimation. Revista Brasileira de Economia, Rio de Janeiro, v. 57, n. 3, p. 605-635, 2003.

MINELLA, A.; et al. Inflation targeting in Brazil: constructing credibility under exchange rate volatility. Working Paper Series, Brasília, n. 77, p. 1-38, 2003.

MISHKIN, F. Inflation targeting in emerging market countries. American Economic Review, v. 9, n. 2, p. 105-109, 2000. 
. International experiences with different monetary policy regimes. Seminar Papers, Stockholm, n. 648, 1998.

. Issues in inflation targeting. In: PRICE stability and long-run target for monetary policy. Ottawa: Bank of Canada, 2001.

. Monetary policy strategy. Cambridge: MIT Press, 2007.

. The economy of money, banking and financial markets. 9th ed. Columbia: Pearson, 2009.

MOENJAK, T. Central banking: theory and practice in sustaining monetary and financial stability. Singapura: John Wiley and Sons, 2014.

NUNES, M. S.; COSTA-JR., N. C. A.; MEURER, R. A relação entre o mercado de ações e as variáveis macroeconômicas: uma análise econométrica para o Brasil. Revista Brasileira de Economia, Rio de Janeiro, v. 59, n. 4, p. 585-607, 2005.

OBSTFELD, M.; ROGOFF, R.The mirage of fixed exchange rates. Journal of Economic Perspectives, Nashville, v. 9, n. 4, p. 73-96, 1995.

PASTORE, A. C. Inflação e crises: o papel da moeda. Rio de Janeiro: Campus, 2015.

PASTORE, A.; PINOTTI, M. C. Inflação e estabilização: algumas lições da experiência brasileira. Revista Brasileira de Economia, Rio de Janeiro, v. 53, n. 1, p. 3-40, 1999.

PIMENTEL, D. M.; LUPORINI, V.; MODENESI, A. M. Assimetrias no repasse cambial para a inflação: uma análise empírica para o Brasil (1999 a 2013). Estudos Econômicos, São Paulo, v. 46, n. 2, p. 343-372, 2016.

RELATÓRIO DE INFLAÇÃO. Brasília, DF: BCB, v. 6, n. 2, 2004.

SENNA, J. J. Política monetária: ideias, experiência e evolução. Rio de Janeiro: Editora FGV, 2010.

SIMS, C. A. Interpreting the macroeconomic time series facts. European Economic Review, Amsterdam, v. 36, n. 5, p. 975-1000, 1992.

SIMS, C. A.; STOCK, J. H.; WATSON, M. W. Inference in linear time series models with some unit roots. Econometrica, Chicago, v. 58, n. 1, p. 113-144, 1990.

SOUZA, F. E. P. Sem medo de flutuar? O regime cambial brasileiro pós-1998. Estudos Econômicos, São Paulo, v. 35, n. 3, p. 519-545, 2005.

TAKEDA, T.; ROCHA, F.; NAKANE, M. I.The reaction of bank lending to monetary policy in Brazil. Revista Brasileira de Economia, Rio de Janeiro, v. 59, n. 1, p. 107-126, 2005.

TAYLOR, J. B. The monetary transmission mechanism: an empirical framework. Journal of Economic Perspectives, Nashville, v. 9, n. 4, p. 11-26, 1995.

TEJADA, C. A. O.; SILVA, A. G. O pass-through das variações da taxa de câmbio para os preços dos principais produtos exportados pelo Brasil. Revista de Economia e Sociologia Rural, Brasília, DF, v. 46, n. 1, p. 171-205, 2008. 
TOBIN, J. A general equilibrium approach to monetary theory. Journal of Money, Credit and Banking, Columbus, v. 1, n. 1, p. 15-29, 1969.

TODA, H. Y.; YAMAMOTO, T. Statistical inference in vector autoregressions with possibly integrated processes. Journal of Econometrics, Amsterdam, v. 66, n. 1, p. 225-250, 1995.

TOMAZZIA, E. C.; MEURER, R. O mecanismo de transmissão da política monetária no Brasil: uma análise em VAR por setor industrial. Economia Aplicada, São Paulo, v. 13, n. 4, p. 371-398, 2009.

UHLIG, $\mathrm{H}$. What are the effects of monetary policy on output? Results from an agnostic identification procedure. Journal of Monetary Economics, Amsterdam, v. 52, n. 2, p. 381-419, 2005.

\begin{tabular}{|c|c|c|c|c|c|c|}
\hline \multicolumn{7}{|c|}{ Âncora cambial } \\
\hline Variável & $\mathrm{ADF}(\mathrm{C})$ & $\mathrm{ADF}(\mathrm{C}+\mathrm{T})$ & DIF & KPSS (C) & KPSS $(\mathrm{C}+\mathrm{T})$ & DIF \\
\hline Lpig & $1 *$ & $1^{*}$ & 1 & $0 *$ & $1 *$ & 1 \\
\hline IPCA & $0 *$ & $1 *$ & 1 & $1 *$ & $1 *$ & 1 \\
\hline Lcamr & $1^{*}$ & $1^{*}$ & 1 & $0 *$ & $1^{*}$ & 1 \\
\hline $\operatorname{Lm} 1$ & $1 *$ & $1^{*}$ & 1 & $1^{*}$ & $0^{*}$ & 1 \\
\hline Locsp & $1^{*}$ & $1^{*}$ & 1 & $1^{*}$ & $1^{*}$ & 1 \\
\hline Lprices & $1 *$ & $1^{*}$ & 1 & $1^{*}$ & $1 *$ & 1 \\
\hline Selic & $1^{*}$ & $1^{*}$ & 1 & $0^{*}$ & $1 *$ & 1 \\
\hline \multicolumn{7}{|c|}{ Metas para inflação } \\
\hline Variável & $\mathrm{ADF}(\mathrm{C})$ & $\mathrm{ADF}(\mathrm{C}+\mathrm{T})$ & DIF & KPSS (C) & KPSS $(\mathrm{C}+\mathrm{T})$ & DIF \\
\hline Lpig & $1^{*}$ & $1^{*}$ & 1 & $1^{*}$ & $1^{*}$ & 1 \\
\hline IPCA & $0 *$ & $0^{*}$ & - & $0^{*}$ & $0^{*}$ & - \\
\hline Lcam & $1 *$ & $1 *$ & 1 & $1^{*}$ & $1 *$ & 1 \\
\hline $\operatorname{Lm} 1$ & $1 *$ & $1^{*}$ & 1 & $1 *$ & $1 *$ & 1 \\
\hline Locsp & $1^{*}$ & $1^{*}$ & 1 & $1 *$ & $1^{*}$ & 1 \\
\hline EI & $1 *$ & $1^{*}$ & 1 & 0* & $1^{*}$ & 1 \\
\hline Selic & $1^{*}$ & $1^{*}$ & 1 & $1^{*}$ & $0^{*}$ & 1 \\
\hline Swap & $1 *$ & $0^{*}$ & 1 & $1 *$ & $1 *$ & 1 \\
\hline
\end{tabular}

Fonte: Elaboração própria a partir dos dados da pesquisa.

Notas: $0^{*}=$ estacionário a $5 \% ; 1^{*}=$ não estacionário a 5\%; DIF refere-se ao número de diferenciações necessárias para a estacionariedade da série.

Recebido em: 29/03/2017. Aceito em: 20/11/2017. 